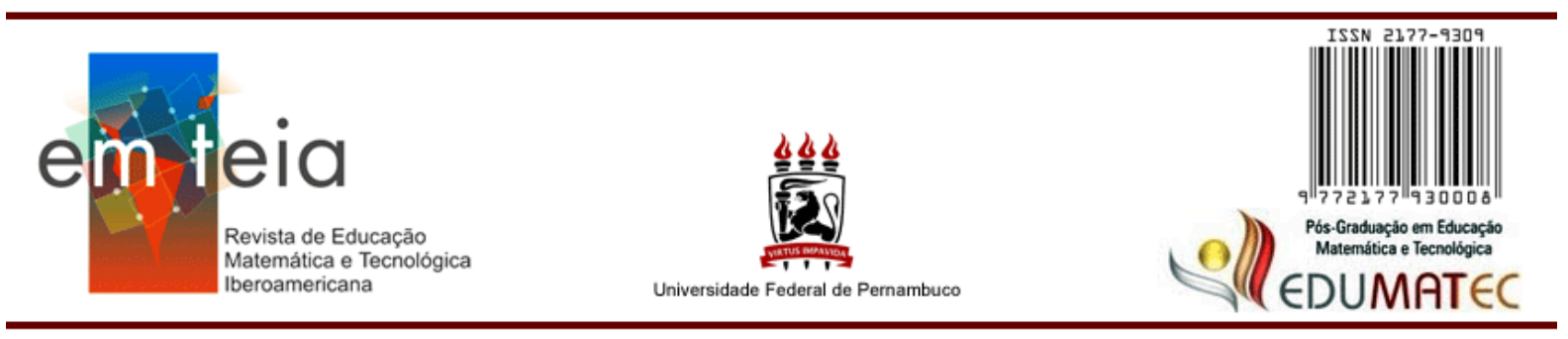

\title{
JOGO DIGITAL CONTRIBUINDO NA COMPREENSÃO DAS OPERAÇÕES COM NÚMEROS NATURAIS E DECIMAIS
}

\author{
Digital game contributing to the understanding of operations with Natural and Decimal \\ numbers
}

\author{
Denise Ritter \\ Doutoranda no Programa de Pós-Graduação em Ensino de Ciências e Matemática \\ Universidade Franciscana (UFN) - Rio Grande do Sul - Brasil \\ deniseritter10@gmail.com \\ https://orcid.org/0000-0003-4720-6543
}

\author{
Ana Marli Bulegon \\ Doutorado em Informática na Educação \\ Universidade Franciscana (UFN) - Rio Grande do Sul - Brasil \\ anabulegon@ufn.edu.br \\ https://orcid.org/0000-0002-4595-7709
}

\section{Resumo}

Os jogos digitais são um recurso que pode ser utilizado no processo de ensino e aprendizagem de conceitos matemáticos. Nessa perspectiva, apresentamos os resultados obtidos com a criação do jogo digital "Ida à padaria" na plataforma FazGame e sua aplicação com uma turma de estudantes do $6^{\circ}$ ano do Ensino Fundamental. O jogo é baseado em uma situação cotidiana e apresenta situações problema sobre as operações com números Naturais e Decimais. Para jogar, cada estudante utilizou seu celular ou um tablet. Percebeu-se que os estudantes estiveram animados durante a atividade com o jogo; efetuaram os cálculos de adição e subtração com facilidade e rapidez e frequentemente, relataram exemplos de situações do cotidiano que envolviam as operações matemáticas, dessa forma, pode-se concluir que a atividade apresentou resultados positivos, diante do modo de pensar matemático das operações com números Naturais e Decimais.

Palavras-Chave: Jogos educacionais digitais. Operações numéricas. Tecnologias móveis. Ensino de Matemática.

\begin{abstract}
Digital games are a resource that can be used in the process of teaching and learning mathematical concepts. In this perspective, we present the results obtained with the creation of the digital game "Ida à bakery" on the FazGame platform and its application with a group of students in the 6th year of Elementary School. The game is based on an everyday situation and presents problem situations regarding operations with Natural and Decimal numbers. To play, each student used his cell phone or a
\end{abstract}


tablet. It was noticed that the students were excited during the activity with the game; performed the addition and subtraction calculations easily and quickly and frequently reported examples of everyday situations involving mathematical operations, thus, it can be concluded that the activity presented positive results, given the mathematical thinking of operations with numbers Natural and Decimal.

Keywords: Digital educational games, numerical operations, mobile technologies, mathematics teaching.

\section{Introdução}

A disciplina de Matemática é temida por muitos estudantes da Educação Básica. Isso, muitas vezes, decorre da dificuldade em aprender seus conceitos e perceber suas aplicações. Nessa perspectiva, a utilização de diferentes recursos/materiais didáticos pode ser importante, pois segundo Lorenzato (2006) os materiais didáticos, quando empregados de forma adequada, despertam o interesse dos estudantes e podem contribuir para uma aprendizagem com compreensão e que tenha significado para o estudante. Ressalta-se, ainda, que, segundo Lorenzato (2006), material didático é qualquer instrumento útil ao processo de ensino e aprendizagem, podendo, dessa forma, ser um livro, uma calculadora, um filme, um jogo, dentre outros. Alves (2015) ressalta que quando um estudante se foca no jogo, suas resistências provenientes da realidade diminuem. Dessa forma, os jogos são uma alternativa que pode contribuir para diminuir o temor dos estudantes em relação à disciplina de matemática.

Os jogos digitais normalmente são desafiadores, pois estimulam o jogador a se superar para atingir os objetivos (ALVES, 2015). Boller e Kapp (2018) destacam que os jogos podem ser ferramentas eficientes e efetivas no ensino, sendo que os jogadores aprendem com os jogos. Ainda nessa perspectiva, segundo Mattar (2010), o aprendizado necessita de motivação para que ocorra um envolvimento intenso do estudante com o conteúdo e isso é atingido com os jogos.

Outro aspecto fundamental no processo de ensino e aprendizagem é que os estudantes percebam em que situações cotidianas são utilizados os conceitos estudados, ou seja, consigam perceber as aplicações do conteúdo a situações reais. Nessa perspectiva, segundo Favorito (2018), os jogos são uma ferramenta que pode auxiliar os estudantes a lidar com problemas do cotidiano.

Neste trabalho apresentamos os resultados da criação e aplicação de um jogo digital educacional, que teve por objetivo auxiliar os estudantes na compreensão das operações com números naturais e decimais. 


\section{Os jogos digitais na educação}

O uso de jogos na educação é algo estudado e discutido há algum tempo. Eles são uma alternativa para despertar o interesse dos estudantes para o conhecimento matemático, dado seu caráter de estratégia, pontuação e possibilidades de superação, por parte dos jogadores, em seus próprios resultados. Conforme Huizinga (1971, p. 33) o jogo é

[...] uma atividade ou ocupação voluntária, exercida dentro de certos e determinados limites de tempo e de espaço, segundo regras livremente consentidas, mas absolutamente obrigatórias, dotado de um fim em si mesmo, acompanhado de um sentimento de tensão e de alegria e de uma consciência de ser diferente da "vida quotidiana".

Para Boller e Kapp (2018), jogo é uma atividade que possui: um objetivo, desafios, regras, interatividade e feedback. Ainda nessa perspectiva, McGonigal (2012, p. 30) diz que “[...] todos os jogos compartilham quatro características que os definem: meta, regras, sistema de feedback e participação voluntária”. Prensky (2012, p. 172) destaca que os jogos possuem seis elementos estruturais que são "Regras, Metas ou objetivos, Resultados e feedback, Conflito/competição/desafio/oposição, Interação, Representação ou enredo". Dessa forma, percebe-se que os jogos possuem elementos que são fundamentais e que constituem a sua essência (BOLLER; KAPP, 2018; MCGONIGAL, 2012; PRENSKY, 2012).

Os jogos podem ser usados para auxiliar no processo de ensino e aprendizagem de diversos conceitos. Nessa perspectiva, conforme Boller e Kapp (2018, p. 40), "Jogos de aprendizagem são destinados a ajudar os jogadores a desenvolver suas habilidades e novos conhecimentos, ou a reforçar os já existentes." Ainda segundo esses autores, "O objetivo final de um jogo de aprendizagem é permitir o alcance de algum tipo de resultado de aprendizagem enquanto o "jogador" está envolvido ou imerso num processo de aprendizado" (BOLLER; KAPP, 2018, p. 40).

A atividade de jogar, quando bem orientada, auxilia no desenvolvimento de habilidades de raciocínio como organização, atenção e concentração, tão necessárias para o aprendizado, em especial da Matemática (BORIN, 2004). Dessa forma, entende-se que os jogos são um recurso pedagógico eficaz para a construção do conhecimento matemático e que contribui para romper os bloqueios que alguns estudantes possuem acerca dessa disciplina.

Prensky (2012, p. 156) aponta aspectos pelos quais os jogos prendem a atenção dos jogadores: 
têm regras, o que nos dá estrutura. Jogos têm metas, o que nos dá motivação. Jogos são interativos, o que nos faz agir. Jogos têm resultados e feedback, o que nos faz aprender. Jogos são adaptáveis, o que nos faz seguir um fluxo. Jogos tem vitórias, o que gratifica nosso ego. Jogos têm conflitos/competições/desafios/oposições, o que nos dá adrenalina. Jogos envolvem a solução de problemas, o que estimula nossa criatividade. Jogos têm interação, o que nos leva a grupos sociais. Jogos têm enredo e representações, o que nos proporciona emoção.

Rosa e Cruz (2019) frisam que jogos digitais são os produzidos para aparelhos eletrônicos como computadores, celulares, videogames, entre outros, tendo como característica principal que sua execução se dá em aparelhos digitais.

Segundo Petry (2016), todos os elementos presentes no jogo, como regras, conflitos, objetivos, definição de pontos e tomada de decisões, são elementos constituintes da vida humana em geral. Em consonância, Cruz, Ramos e Albuquerque (2012) salientam que ao jogar os jogadores exercitam sua inteligência e o que se aprende nos jogos pode contribuir nos processos de aprendizagem do cotidiano. Dessa forma, os jogos podem auxiliar o jogador a enfrentar desafios e resolver problemas em sua vida cotidiana.

As características que formam o conceito de jogo, segundo Petry (2016), são: liberdade, regras, produção de um estado de ânimo, capacidade de modificação de regras durante o jogo, a possível existência de conflitos que estimulem os jogadores a superá-los, objetivos intrínsecos ou formulados pelos jogadores, a circunscrição de pontos de partida e pontos de final do jogo, a possibilidade de tomada de decisões por parte do jogador.

Os jogos digitais possibilitam ao jogador a experimentação de situações virtuais protegidas e também exigem que o jogador saiba lidar com eventos não controlados por ele. Os jogos digitais são propiciadores de situações de aprendizagem, pois, ao jogar, o jogador reforça suas estruturas cognitivas (PETRY, 2016). Porém, para que ocorra aprendizagem é necessário que o estudante se envolva com as atividades e isso é proporcionado nos jogos digitais. Além disso, os jogos possibilitam aos estudantes desenvolver uma série de habilidades e o aprendizado de forma colaborativa (MATTAR, 2010). Conforme Mesquita, Aranha e Silva (2018, p. 875), “A junção entre aprender e jogar causa uma maior imersão dos jogadores no conteúdo educativo apresentado, de maneira que assimilem mais efetivamente, e os instiga a aprender com os próprios erros".

Bartoszeck, Czeszak e Neto (2016) colocam que o jogo deve agregar um conteúdo significativo para o estudante, ou seja, deve fazer sentido para ser utilizado por ele. Ainda segundo esses autores, se os desafios do jogo forem muito fáceis o jogador ficará entediado, se os desafios forem muito difíceis podem produzir sentimentos de angústia e tristeza no jogador. Dessa forma, Bartoszeck, Czeszak e Neto (2016, p. 10) evidenciam que “[...] o jogo digital 
deverá proporcionar desafios progressivos, a cada aumento da habilidade do jogador, a dificuldade deverá aumentar proporcionalmente".

\section{Trabalhos relacionados}

A fim de analisar as contribuições da criação e aplicação de jogos digitais educativos, propostos neste trabalho, realizamos inicialmente uma busca na literatura científica visando encontrar trabalhos afins que nos ajudassem a responder ao objetivo da pesquisa. Nesta seção, serão citados os textos encontrados que mais se aproximam da nossa temática.

Azevedo, Machado e Lyra-Silva (2020) tiveram por intuito compreender o processo da construção de conhecimento matemático a partir da produção de jogos digitais por alunos do $6^{\circ}$ ano do Ensino Fundamental no Scratch. Os autores ressaltam que os resultados obtidos indicam que a produção de conhecimento a partir da produção de jogos se dá de forma dinâmica, evidenciando a importância de um ensino contextualizado em que o estudante possa assumir uma postura ativa com o uso da linguagem de programação.

Pereira, Doneze e Pansanato (2018) adaptaram e aplicaram um jogo de trilha no formato digital, construído no Excel. O objetivo do jogo era auxiliar os estudantes na compreensão dos Números Inteiros - Decimais e suas operações. Os autores concluíram que os estudantes participantes do estudo tiveram facilidade em resolver operações de adição de números inteiros e decimais, já na realização de operações de subtração eles tiveram dificuldade, sendo estas sanadas após a aplicação da proposta.

Pires, Filho, Alencar e Almeida (2018) apresentam o desenvolvimento de um Jogo Sério denominado "Tricô numérico". O jogo é de ação do tipo plataforma e tem por objetivo promover a aprendizagem matemática juntamente com o desenvolvimento do pensamento computacional. O referido jogo é destinado à aprendizagem das quatro operações e oferece segundo os autores a possibilidade de diversão e entretenimento para todos os públicos.

Souza et al. (2018) descrevem em seu trabalho o processo de desenvolvimento de um jogo sério para o ensino de matemática, abordando o conteúdo das quatro operações. O jogo intitulado “Operação Monstro" utiliza aspectos lúdicos para promover a aprendizagem de forma divertida.

Soares, Souza e Castro (2018) tiveram por objetivo analisar um recurso educacional digital para auxiliar estudantes do $2^{\circ}$ ano do Ensino Fundamental na compreensão de conceitos aditivos. O respectivo jogo intitulado "Caminhos da Matemática" é um RED desenvolvido a partir do software de programação Construct. Os autores destacam que a versão atual do jogo 
cumpre os objetivos inicialmente propostos, mas para estudos futuros necessita de atualização de alguns elementos de interação.

Pires, Queroga, Teixeira e Filho (2018) tratam do desenvolvimento de um aplicativo para a alfabetização matemática. O jogo foi intitulado "AmazonMath" e teve como objetivo promover a alfabetização matemática proporcionando ao jogador experiências lúdicas através da interação com o personagem, sendo que o jogador executa as missões que lhe são propostas via áudio.

Os trabalhos citados utilizam diferentes jogos digitais e plataformas para sua criação. Ressalta-se que "A escolha dos jogos educacionais que serão utilizados em sala de aula também exige um olhar crítico dos docentes com relação ao potencial do material como motivador e facilitador da construção do conhecimento" (SILVA-PIRES; TRAJANO; ARAUJO-JORGE, 2020, p. 15). Nessa perspectiva, neste estudo foi criado e utilizado o jogo educacional digital "Ida à padaria", pois acredita-se que ele irá motivar os estudantes e irá contribuir na compreensão dos conceitos.

\section{Metodologia}

A atividade descrita neste trabalho teve por objetivo auxiliar na compreensão das operações com números naturais e decimais. Ela foi desenvolvida com uma turma de 10 estudantes do $6^{\circ}$ ano do Ensino Fundamental de uma escola pública do interior do estado do Rio Grande do Sul, tendo duração de uma hora aula de 40 minutos. A escola em que as atividades foram desenvolvidas não possuía laboratório de informática; dessa forma optou-se por utilizar os celulares dos estudantes e alguns tablets, disponibilizados pela professora, para aqueles estudantes que não possuíam celular.

Os estudantes já haviam estudado as operações com números naturais (soma, subtração, multiplicação e divisão), assim como as operações de soma e subtração com números decimais, também já haviam resolvido exercícios sobre esses conceitos. Dessa forma, o jogo foi utilizado para que os estudantes pudessem revisar e reforçar essas operações, considerando que, conforme Prensky (2012, p. 496), “[...] os jogos são uma boa maneira de fazer que os aprendizes revisem o que aprenderam".

O jogo digital "Ida à padaria", aqui descrito, foi criado pelas pesquisadoras na plataforma FazGame (https://www.fazgame.com.br/) cuja tela inicial pode ser vista na Figura 1. 
Figura 1 - Tela inicial da plataforma FazGame

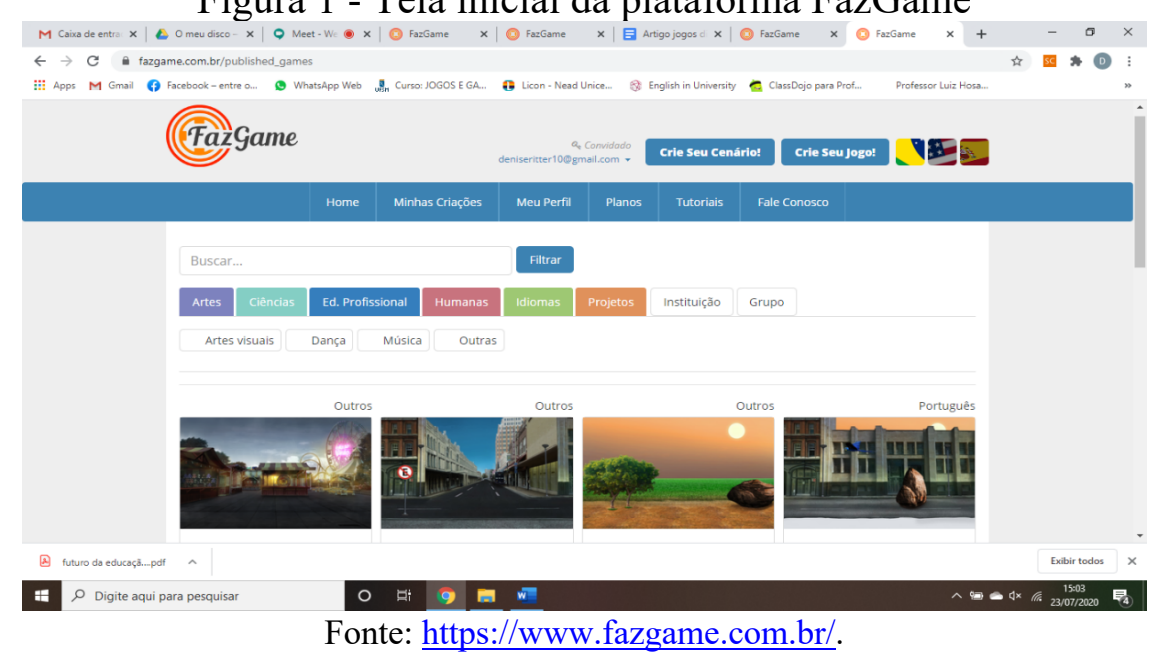

O FazGame é uma plataforma que possui ambiente lúdico e intuitivo para criação de jogos digitais educacionais. Essa ferramenta está associada ao Portal FazGame, possibilitando, dessa forma, a publicação e o acesso aos jogos digitais em qualquer momento que o usuário desejar. Oferece opção de acesso gratuito e é de fácil navegação. Na própria página do FazGame estão disponíveis vídeos com tutoriais para auxiliar na criação dos jogos. Possibilita que os usuários criem jogos digitais educacionais sem ter conhecimento de programação e design. $\mathrm{Na}$ criação do jogo é possível escolher os cenários e os personagens a partir da narrativa que se deseja abordar. Esses aspectos permitem que tanto professores quanto estudantes elaborem seus jogos.

A criação do jogo no FazGame se dá pela elaboração e configuração de cenas em que podem ser adicionados mensagens, diálogos, recompensas, entre outros. Dessa forma, para criar um jogo é necessário inicialmente pensar e elaborar uma narrativa que se dará em um determinado espaço (cenário), escolher os personagens que irão interagir e seguir o percurso do jogo a partir da narrativa. Durante esse percurso podem ser inseridos questionamentos para o jogador responder e atribuídas recompensas caso as respostas estejam corretas. Na figura 2 pode ser observada a estrutura da primeira cena do jogo digital "Ida à padaria" (https://www.fazgame.com.br/published_games/1232). 
Figura 2 - Estrutura da primeira cena do jogo digital "Ida à padaria"

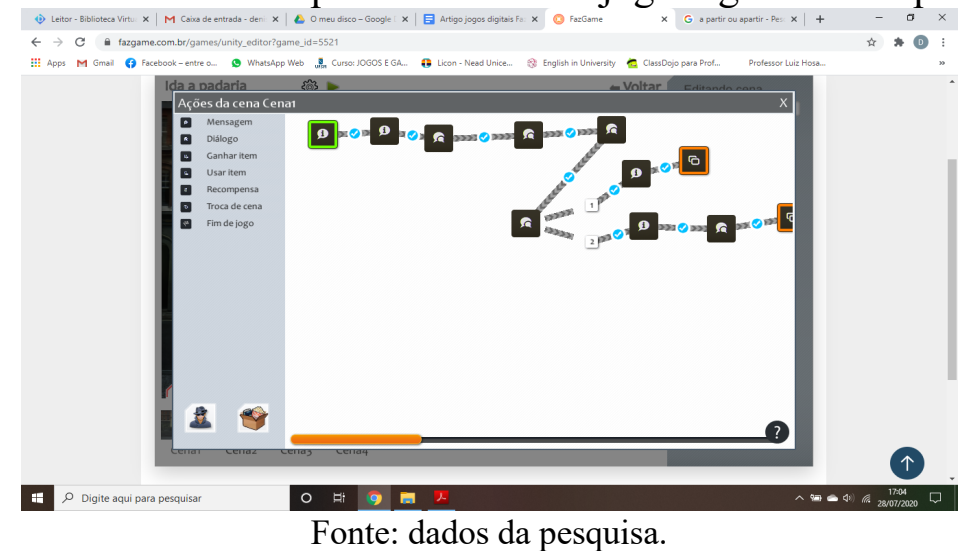

O jogo possui personagens que vivenciam uma situação cotidiana, na qual precisam administrar uma certa quantia. As operações matemáticas, presentes no jogo, estimulam as habilidades de cálculo mental relacionadas às operações com números naturais e decimais e promovem a educação financeira. Na Figura 3 pode-se ver a tela inicial do jogo.

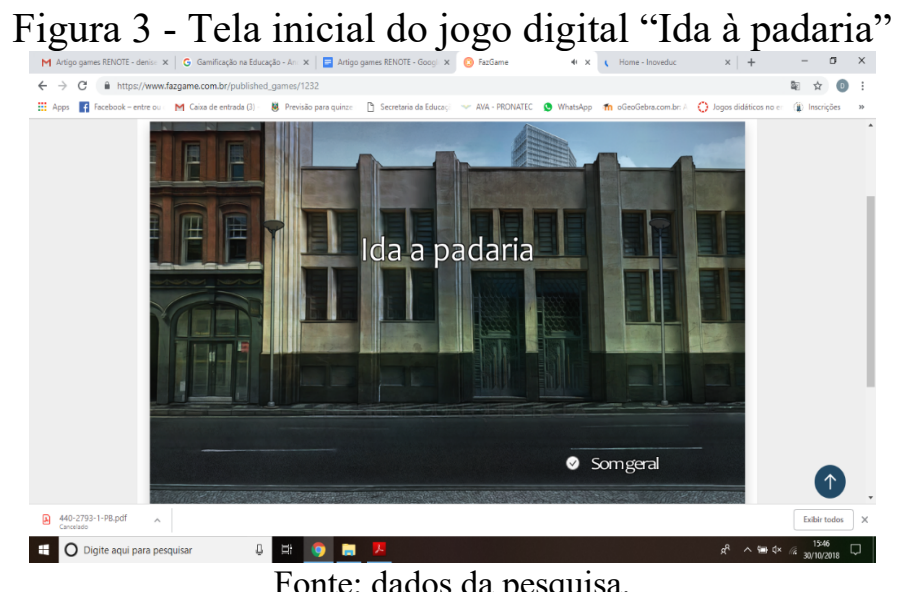

O jogo não possui regras explícitas, pois ele é totalmente intuitivo, sendo que o jogador precisa ler a narrativa e assinalar a resposta que considera correta quando são propostos questionamentos por meio de situações-problema, no contexto de compra e venda de produtos. A dinâmica do jogo é a seguinte: duas crianças precisam se deslocar de casa e ir a uma padaria fazer compras. Para isso eles recebem dinheiro de seu pai e uma lista de produtos para comprar, além de precisar tomar um ônibus para o deslocamento. Em todas as situações-problema propostas é necessário que os usuários saibam resolver operações de soma e subtração com números naturais e decimais. Por exemplo: o pai das crianças deu a eles $\mathrm{R} \$ 20,00$ para ir à padaria. A menina pediu para comprar sonhos. Então o pai lhes deu mais R\$10,00. Depois 
disso lhes foi perguntado: "Quanto dinheiro temos no total?" (Figura 4). Os estudantes deveriam escolher entre duas alternativas: R\$20,00 e R\$30,00.

Figura 4 - Exemplo de situação-problema do jogo

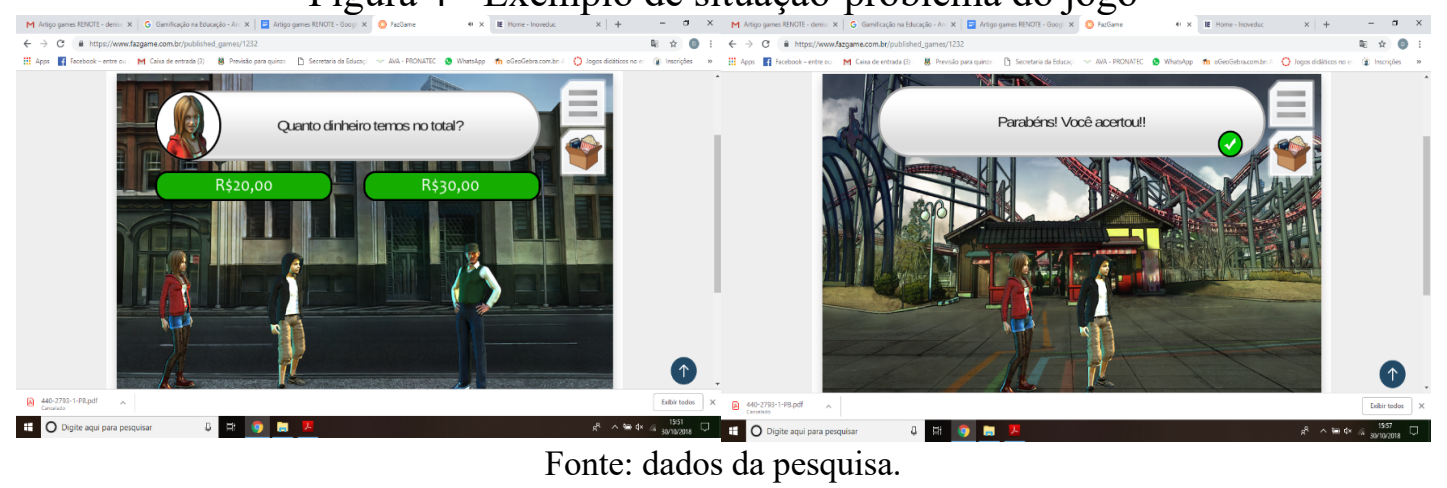

Ao clicar na resposta correta o jogador ganha 10 pontos e segue para a próxima tela. Caso o jogador não clique na resposta correta ele não recebe pontos, mas também segue para a próxima tela para que possa continuar jogando e respondendo os questionamentos propostos. O jogo também possui outras questões como: “As passagens de ônibus custavam R 2,50 cada uma. Então quanto custam duas passagens de ônibus?”. A cada operação é necessário que o jogador verifique quanto dinheiro ainda restava, para que pudesse fazer as operações seguintes. Desse modo, estavam constantemente realizando as operações numéricas e, conforme respondiam de forma correta, iam acumulando pontos. Nessa perspectiva, Boller e Kapp (2018, p. 103) ressaltam que "Se um jogador está assimilando o conteúdo de um jogo, o seu placar deve refletir isso de forma positiva. Em contrapartida, caso não ocorra a aprendizagem, também é no placar eu tal dificuldade deverá ser representada”. Dessa forma, é possível verificar se o estudante está conseguindo reforçar o conteúdo através de seu desempenho no jogo.

Para o desenvolvimento da atividade com o jogo digital foram seguidas as orientações propostas por Boller e Kapp (2018). Segundo esses autores, os melhores resultados ao utilizar um jogo de aprendizagem são atingidos quando é utilizado um processo de três passos

[...] primeiro um instrutor ou um conjunto de instruções on-line é usado para introduzir o jogo e explicar aos participantes os objetivos de aprendizagem; em seguida os participantes jogam o jogo; o terceiro e último passos diz respeitos ao "depois", quando instrutor e jogadores discutem o que foi aprendido e de que modo os eventos do jogo darão sustentação aos objetivos instrucionais. (BOLLER; KAPP, 2018, p. 46).

Dessa forma, percebe-se que esses autores ressaltam a importância de ter claro os objetivos de aprendizagem e discuti-los com os estudantes, para que a utilização do jogo contribua efetivamente no processo de ensino e aprendizagem dos estudantes. 


\section{Resultados e discussões}

Seguindo as orientações propostas por Boller e Kapp (2018), inicialmente foi conversado com os estudantes explicando que o jogo "Ida à padaria" possui operações com números naturais e decimais que eles deveriam resolver; foi ressaltado também que em alguns momentos do jogo não eram propostos questionamentos mas que era importante acompanhar a narrativa e as operações envolvidas para que fosse possível administrar a quantidade de dinheiro, tendo ciência dos gastos e controle da quantidade ainda disponível.

Para ter acesso ao jogo os estudantes tiveram de realizar um cadastro na plataforma FazGame. Efetuado esse cadastro se deu o segundo momento proposto por Boller e Kapp (2018) em que os estudantes jogaram o jogo. Durante o jogo à medida que o jogador responde de forma correta os questionamentos ele vai acumulando pontos, sendo que no final do jogo ele pode consultar o total de pontos obtidos, como pode ser observado na Figura 5.

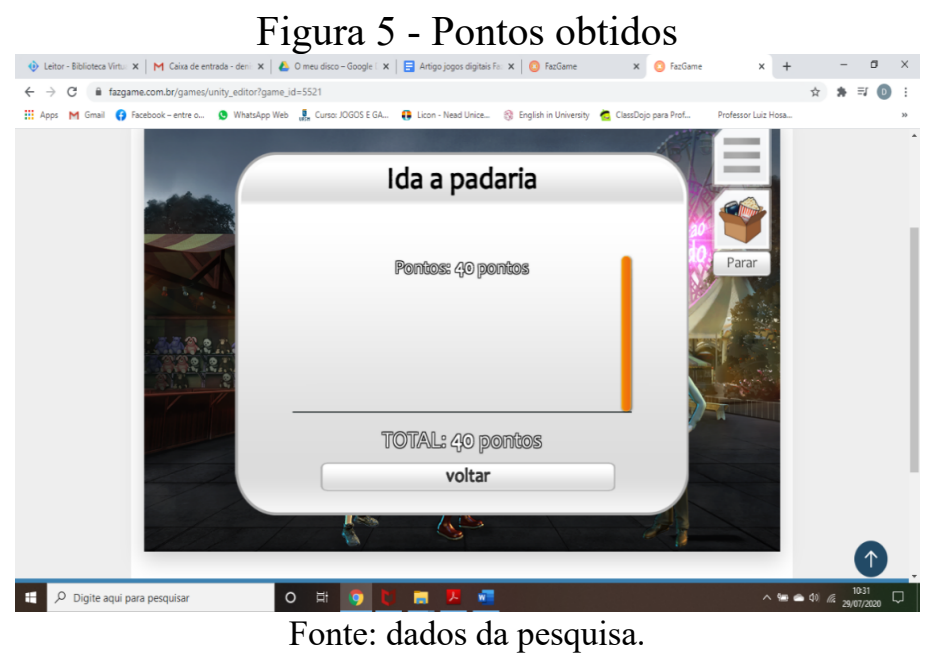

Durante o jogo, foi acompanhada a pontuação obtida pelos estudantes para verificar se estes estavam conseguindo reforçar os conteúdos, como ressaltado por Boller e Kapp (2018, p. 104) “[...] um placar oferece feedback sobre quão bem um indivíduo está se saindo num jogo". Dessa forma, segundo esse autor, o escore deve auxiliar o jogador a avaliar seu desempenho em relação ao domínio do conteúdo. Nessa perspectiva, a partir do acompanhamento do escore dos jogadores foi possível identificar os estudantes que estavam com dificuldade e auxiliá-los de forma individual. 
O manuseio com esse jogo deixou os estudantes muito animados; eles efetuaram os cálculos resolvendo com entusiasmo as situações-problema propostas. Nessa perspectiva McGonigal (2012, p. 37) ressalta que "Todos os sistemas neurológicos e fisiológicos que estão na base da felicidade - nossos sistemas de atenção, nosso centro de recompensas, nossos sistemas de motivação, nossos centros de emoção e memória - são inteiramente ativados com os jogos".

Percebeu-se também que durante o jogo os estudantes faziam comentários em relação a situações do seu cotidiano que se assemelham às vivenciadas no jogo. Nessa perspectiva, SilvaPires, Trajano e Araujo-Jorge (2020) salientam que os conhecimentos aprendidos durante um jogo possibilitam a construção de novos conhecimentos contribuindo com o desenvolvimento cognitivo do estudante de forma contextualizada.

Após o jogo foi realizada uma discussão com os estudantes, caracterizando o terceiro momento proposto por Boller e Kapp (2018). Essa discussão teve por intuito identificar as percepções deles em relação ao jogo e aos conceitos envolvidos. Os estudantes ressaltaram que gostaram de gerenciar o dinheiro dos irmãos Fernanda e Mateus, sendo o jogo uma oportunidade de trabalhar com educação financeira, visto que conforme destacado pelos estudantes eles em seu cotidiano também precisam gerenciar o dinheiro que recebem dos pais na mesada, por exemplo. Também destacaram que o jogo envolvia diversas situações em que precisaram realizar operações com números naturais e decimais, sendo que conseguiram perceber exemplos de situações cotidianas em que esses conceitos são utilizados.

Dessa forma, os estudantes puderam utilizar e reforçar seus conhecimentos, estabelecer relações com situações cotidianas e compreender melhor a importância da educação financeira no cotidiano e na vida.

O jogo foi uma forma divertida de os estudantes exercitarem seus conhecimentos e aprenderem. Os resultados aqui obtidos corroboram Prensky (2012) acerca da diversão que os jogos causam. Para esse autor, os jogos e o ato de jogar ajudam a ensinar. Percebeu-se ainda que o jogo deixou os estudantes bastante envolvidos e motivados. Nesse contexto, Prensky (2012) ressalta que os jogos de aprendizagem quando bem projetados de fato produzem aprendizagem, muitas vezes, por meio do envolvimento que proporcionam.

Diante dos resultados expostos pode-se inferir que os jogos digitais são recursos das Tecnologias Digitais de Informação e Comunicação (TDIC) que quando utilizados de forma adequada motivam os estudantes e podem contribuir no processo de ensino e aprendizagem. Nessa perspectiva, Almeida (2007) ressalta que o uso das TDIC no contexto educativo 
possibilita a integração dos conceitos e estratégias mobilizados e representados pelos estudantes para a sua aprendizagem.

\section{Considerações finais}

O objetivo da criação e utilização do jogo digital "Ida à padaria" era auxiliar na compreensão das operações com números naturais e decimais. Percebeu-se que os estudantes estiveram animados durante as atividades, realizavam os cálculos de adição e subtração com facilidade e rapidez. O jogo também possibilitou aos estudantes identificar as aplicações desses conceitos em situações cotidianas e isso potencializou a aprendizagem dos conceitos de operações matemáticas. Dessa forma, ficou evidente que o jogo motivou os estudantes e segundo Mattar (2010) o aprendizado precisa de motivação para um envolvimento intenso o que é atingido com os jogos digitais. Outro aspecto relevante é que o jogo evidenciou a importância da educação financeira a partir de uma situação em que os estudantes tiveram que gerenciar uma certa quantia de dinheiro.

Ressalta-se que o professor pode buscar jogos digitais em repositórios, criar seus próprios jogos e ainda estimular os estudantes a criarem jogos. Todas essas possibilidades são alternativas que podem ser adotadas no processo educacional e que se planejadas e executadas de forma adequada, tendo claros os objetivos e a intencionalidade pedagógica, contribuem para a aprendizagem dos estudantes. Dessa forma, destaca-se o importante papel do professor nesse processo, para que a partir dos conhecimentos que possui e tendo claros os objetivos que deseja atingir possa escolher o melhor recurso a ser utilizado em determinada situação de ensino.

A plataforma FazGame utilizada para criação do jogo digital é de fácil manuseio e acessibilidade permitindo que tanto professores quanto estudantes possam criar jogos. É uma plataforma que não exige conhecimentos de programação para criação dos jogos sendo que o manuseio se dá de forma intuitiva. Além disso, possui a opção de acesso gratuito, sendo desta forma um recurso que pode ser utilizado em diversas situações e disciplinas no contexto educativo para potencializar a aprendizagem de forma lúdica.

Pode-se concluir que a atividade apresentou resultados positivos, diante do modo de pensar matemático, salientando que o uso das tecnologias pode auxiliar na compreensão dos conceitos matemáticos, indo ao encontro das ideias de Petry (2016) de que os jogos quando bem projetados de fato produzem aprendizagem. 
Ressalta-se ainda que esse tipo de atividade também pode ser desenvolvido em outros contextos, como por exemplo, no Ensino Médio, na Educação Profissional e Tecnológica e até no Ensino Superior, e cabe ao professor definir a partir de sua intencionalidade pedagógica qual o tipo de jogo mais adequado para cada contexto.

\section{Referências}

ALMEIDA, M. E. B. de. Tecnologias digitais na educação: o futuro é hoje. In: E - TIC $5^{\circ}$ Encontro de Educação e Tecnologia de informação e comunicação, 2007, Rio de Janeiro. Anais... Rio de Janeiro: 2007, p. 1-17. Disponível em: https://etic2008.files.wordpress.com/2008/11/pucspmariaelizabeth.pdf . Acesso em: 05 mar. 2020.

ALVES, F. Gamification: como criar experiências de aprendizagem engajadoras: um guia completo: do conceito à prática. São Paulo: DVS Editora, 2015.

AZEVEDO, G. T. de; MACHADO, J. P. R.; LYRA-SILVA, G. M. V. Processo de construção de conhecimento matemático: algoritmos e jogos digitais. EM TEIA - Revista de Educação Matemática e Tecnológica Iberoamericana. Recife, v. 11, n. 1, p. 1-23, 2020.

BARTOSZECK, F. K.; CZESZAK, W. A. A. C.; NETO, J. A. de M. Um exemplo de sabedoria digital: a aprendizagem baseada em games. Revista Científica de Educação a Distância. Santos, v. 8, n. 14, p. 1-26, 2016.

BOLLER, S.; KAPP, K. Jogar para Aprender: tudo o que você precisa saber sobre o design de jogos de aprendizagem eficazes. São Paulo: DVS Editora, 2018.

BORIN, J. Jogos e Resolução de Problemas: uma estratégia para as aulas de Matemática. São Paulo: IME-USP, 2004.

CRUZ, D. M.; RAMOS, D. K.; ALBUQUERQUE, R. M. de. Jogos eletrônicos e aprendizagem: o que as crianças e os jovens têm a dizer? Revista Contrapontos Eletrônica, v. 12, n. 1, p. 87-96, 2012.

FAVORITO, J. Como implementar a gamificação dentro da sala de aula. INOVEDUC, 2018. Disponível em: <www.inoveduc.com.br>. Acesso em: 10 nov. 2019.

HUIZINGA, J. Homo Ludens: o jogo como elemento da cultura. São Paulo: Perspectiva, 1971.

LORENZATO, S. Laboratório de ensino de matemática e a materiais didáticos. In: LORENZATO, S. O Laboratório de ensino de matemática na formação de professores. Campinas, SP: Autores Associados, 2006. p. 3-37. 
MATTAR, J. Games em educação: como os nativos digitais aprendem. São Paulo: Pearson Prentice Hall, 2010.

MCGONIGAL, J. A realidade em jogo. Rio de Janeiro: BestSeller, 2012.

MESQUITA, H. O.; ARANHA, E. H. da S.; SILVA, T. R. da. Uma Abordagem para o Desenvolvimento de Jogos Digitais Educativos no Ensino Básico. In: SBIE, XXIX, 2018, Fortaleza, p. 874-883. Anais... Fortaleza: 2018. Disponível em: https://brie.org/pub/index.php/sbie/article/view/8047. Acesso em: 02 jul. 2020.

PEREIRA, F. F.; DONEZE, I. S.; PANSANATO, L. T. E. Números Inteiros e Decimais: uma abordagem dos conteúdos de Matemática por meio de um jogo frente às dificuldades do cenário tecnológico da educação Básica. Revista Prática Docente. Confresa, v. 3, n. 2, p. 386-405, jul/dez, 2018.

PETRY, L. C. O conceito ontológico de jogo. In: ALVES, L.; COUTINHO, I. de J. Jogos digitais e aprendizagem: fundamentos para uma prática baseada em evidências. Campinas, SP: Papirus, 2016. p. 17-42.

PIRES, F. G. de S.; FILHO, J. C. da S. D.; ALENCAR, L. F. B. de; ALMEIDA, W. D. M. de. Tricô numérico: Um jogo para alfabetização matemática. In: WCBIE, VII, 2018, Fortaleza. Anais... Fortaleza: 2018, p. 249-255 . Disponível em: https://www.brie.org/pub/index.php/wcbie/article/view/8238. Acesso em: 25 jun. 2020.

PIRES, F. G de S.; QUEROGA, J. da S.; TEIXEIRA, K. B.; FILHO, J. C. da S. D. AmazonMath: um jogo educativo voltado para alfabetização matemática. In: WCBIE, VII, 2018, Fortaleza. Anais... Fortaleza: 2018, p. 280-287. Disponível em: https://www.brie.org/pub/index.php/wcbie/article/view/8244. Acesso em: 05 jul. 2020.

PRENSKY, M. Aprendizagem baseada em jogos digitais. São Paulo: Editora Senac São Paulo, 2012.

ROSA, J. da; CRUZ, D. M. Análise de Jogos em sites Educativos. In: WIE, XXV, 2019, Brasília. Anais... Brasília: 2019, p. 994-1003. Disponível em: https://www.brie.org/pub/index.php/wie/article/view/8600. Acesso em: 7 jul. 2020.

SILVA-PIRES, F. do E. S.; TRAJANO, V. da S.; ARAUJO-JORGE, T. C. de. A Teoria da Aprendizagem Significativa e o jogo. Revista Educação em Questão. Natal, v. 58, n. 57, p. 1-21, e-21088, jul./set. 2020.

SOARES, C. G.; SOUZA, D. do C. de; CASTRO, J. B. de. Recursos Educacionais Digitais e o ensino de adição e subtração: a concepção de um jogo na perspectiva da Teoria dos Campos Conceituais. In: WCBIE, VII, 2018, Fortaleza, p. 361-364. Anais... Fortaleza: 2018.

Disponível em: https://www.br-ie.org/pub/index.php/wcbie/article/view/8260. Acesso em: 22 jun. 2020. 
SOUZA, F. A. de; SANTOS, B. B. dos; SILVA, M. R. B. da; RODRIGUES, A. N.;

BARRETO, F. F. Processo de desenvolvimento de um Jogo Sério para o ensino das Quatro Operações Matemáticas. In: WCBIE, VII, 2018, Fortaleza, p. 1147-1156. Anais... Fortaleza: 2018. Disponível em: https://www.br-ie.org/pub/index.php/wcbie/article/view/8343. Acesso em: 20 jun. 2020.

\section{Agradecimentos}

Recebido em 28 de setembro de 2020. Aprovado em 18 de novembro de 2020.

O presente trabalho foi realizado com apoio da Coordenação de Aperfeiçoamento de Pessoal de Nível Superior - Brasil (CAPES) - Código de Financiamento 001. 